\title{
General Psychiatry Effects of the combination of second- generation antipsychotics on serum concentrations of aripiprazole and dehydroaripiprazole in Chinese patients with schizophrenia
}

Ping Jiang, ${ }^{1,2}$ Xiujia Sun (1) , ${ }^{1,2}$ Juanjuan Ren, ${ }^{1,2}$ Hongmei Liu, ${ }^{1,2}$ Zhiguang Lin, ${ }^{1,2}$ Junwen Liu, ${ }^{1,2}$ Xinyu Fang, ${ }^{1,2}$ Chen Zhang ${ }^{1,2}$

To cite: Jiang $P$, Sun $X$, Ren J, et al. Effects of the combination of secondgeneration antipsychotics on serum concentrations of aripiprazole and dehydroaripiprazole in Chinese patients with schizophrenia. General Psychiatry 2021;34:e100423. doi:10.1136/ gpsych-2020-100423

Received 08 October 2020 Revised 17 December 2020 Accepted 28 January 2021

\section{Check for updates}

(C) Author(s) (or their employer(s)) 2021. Re-use permitted under CC BY-NC. No commercial re-use. See rights and permissions. Published by BMJ.

${ }^{1}$ Department of Biochemistry and Psychopharmacology,

Shanghai Mental Health Center, Shanghai, China

${ }^{2}$ Shanghai Key Laboratory of Psychotic Disorders, Shanghai, China

Correspondence to

Dr Chen Zhang;

zhangchen645@gmail.com

\section{ABSTRACT}

Background Aripiprazole (ARI) is often prescribed alone or in combination with other second-generation antipsychotics (SGAs) to treat patients with schizophrenia. However, this may increase the potential clinical significance of drug-drug interactions. Therapeutic drug monitoring (TDM) is an important and fundamental tool both when administering ARI alone and in combination with other SGAs to monitor ARI pharmacokinetics, adjust the dosage and thereby achieve more effective and safer treatment.

Aims This study retrospectively investigated the effects of four SGA comedications (clozapine, risperidone, quetiapine (QTP) and olanzapine) and other potential factors (sex, age and ARI dose) on the serum concentrations of ARI and dehydroaripiprazole (DARI) in Chinese patients with schizophrenia using TDM data.

Methods High-performance liquid chromatography was used to test the serum concentrations of ARI, DARI and ARI+DARI. In addition, steady-state dose-adjusted serum concentrations (ie, concentration-to-dose ratios, C:D ratios) of ARI, DARI and ARI+DARI; sex; age; ARI dose and SGA comedication dose between 299 inpatients with schizophrenia who received ARI or SGA comedication were all collected and analysed. Spearman's correlation and multiple linear regression analysis were used to evaluate bivariate associations between ARI dose and serum ARI and DARI concentrations and describe the effect of independent variables on serum ARI and DARI concentrations, respectively.

Results There were significant differences in the $C: D$ ratios of $A R I\left(\chi^{2}=-3.21, p=0.001\right)$ and $A R I+D A R I$ $\left(\chi^{2}=-2.50, p=0.01\right)$ between the ARI and SGA groups, as well as in the $C: D$ ratios of $A R I\left(\chi^{2}=-3.59, p<0.001\right)$ and ARI+DARI $\left(\chi^{2}=-3.10, p=0.002\right)$ between the female patients in the two groups. Of the four SGAs, only QTP had significant effects on the $C: D$ ratios of $A R I(Z=-4.12$, $p<0.001)$ and $A R I+D A R I(Z=-3.62, p<0.001)$ when compared with the ARI group in the whole sample and on the $\mathrm{C}: \mathrm{D}$ ratios of ARI, DARI and ARI+DARI $(Z=-3.96$, $p<0.001 ; Z=-2.22, p=0.03 ; Z=-3.75, p<0.001$, respectively) in women when compared with their counterparts in the ARI group.
Conclusion Comedication with SGAs resulted in lower C:D ratios of $A R I$ and $A R I+D A R I$ compared with $A R I$ monotherapy, and comedication with QTP resulted in lower $\mathrm{C}: D$ ratios of $A R I$ and $A R I+D A R I$ than $A R I$ monotherapy. Despite this statistical significance of our findings, whether the presently observed effect has clinical significance requires exploration by further research. TDM and dosage regulation of $A R I$ should be performed in Chinese inpatients with schizophrenia who are receiving SGA comedication (especially QTP) to maintain a safe and effective dose-adjusted serum concentration of ARI and DARI.

\section{INTRODUCTION}

Aripiprazole (ARI) is a novel secondgeneration antipsychotic (SGA) with a unique pharmacological profile: it acts as a partial agonist at dopamine D2 receptors, an antagonist at 5-HT2A receptors and a partial agonist at serotonin $1 \mathrm{~A}$ receptors. It is effective in treating psychiatric disorders, especially schizophrenia and schizoaffective disorders. Compared with other antipsychotic drugs, ARI induces fewer adverse effects and has a lower potential for causing extrapyramidal adverse effects, weight gain, hyperlipidaemia, hyperprolactinaemia and sedation. ${ }^{1-7}$ Furthermore, ARI decreases the risk of relapse in patients up to the medium term and is associated with better patient compliance. $^{2-6}$

ARI is often prescribed in combination with other SGAs to treat schizophrenia with comorbid psychiatric illnesses, control the side effects of ARI or to augment its therapeutic effect. However, this practice may result in drug-drug interactions and subsequent changes in the serum concentrations of ARI, further resulting in clinical toxicity or reduced therapeutic effects. Therapeutic 
drug monitoring (TDM) and dosage adjustments of ARI have been suggested in clinical practice as strategies to minimise poor drug compliance in patients with schizophrenia and schizoaffective disorders, as well as to avoid adverse effects. ${ }^{67}$

SGA polypharmacy (a combination of two or more SGAs) and pharmacological add-on therapy with SGAs are increasingly being prescribed to patients with schizophrenia because they have an elevated risk of developing other psychiatric conditions, such as anxiety disorders or depression, for which they are more likely to receive other concomitant therapies. ${ }^{8-10}$ The lack of response to treatment with SGA and the deterioration of the mental health of a patient are absolute indications for determining the frequency of SGA intake and the serum concentration of the SGA and its metabolites. Accordingly, the frequent use of a combination of two SGAs to potentiate their actions requires TDM to monitor the patient's SGA intake and serum concentrations of the SGAs and their metabolites.

As there are limited studies available on the effects of comedicating SGAs on the pharmacokinetics of ARI, this study aimed to investigate the effect of SGA comedication on serum concentrations of ARI and its main metabolite, dehydroaripiprazole (DARI), in Chinese patients with schizophrenia. ${ }^{11-14}$

\section{MATERIALS AND METHODS}

To investigate the pharmacokinetic effects of four comedicated SGAs (clozapine (CLZ), risperidone (RIP), quetiapine (QTP) and olanzapine (OLZ) ) and other potential influencing factors (sex, age, ARI dose and SGA comedication) on the serum concentrations of ARI and DARI in Chinese inpatients with schizophrenia, we retrospectively analysed the potential effects of these factors on the serum concentrations of ARI, DARI and ARI+DARI as well as the C:D ratios of ARI, DARI and ARI+DARI in 299 patients with schizophrenia. We aimed to provide a reference for TDM and ARI dose regulation in the treatment of Chinese inpatients with schizophrenia receiving SGA comedication.

\section{Patients and inclusion criteria}

A retrospective study was performed of inpatients with schizophrenia who were treated in our centre from January 2010 to March 2014. Initially, 363 patients were selected for inclusion in the study, but 299 remained following three screening rounds for compliance according to the patient inclusion criteria shown in figure 1. Patients were treated with ARI monotherapy or ARI in combination with one of four SGAs (CLZ, RIP, QTP and OLZ). The clinical data (serum ARI and DARI concentrations, ARI dose, SGA comedication and SGA dose) and demographic data (sex and age) of the patients had been previously obtained from medical archives, and the serum ARI+DARI concentration and C:D ratios of ARI, DARI and ARI+DARI were calculated from the clinical data. The serum ARI and DARI concentrations were

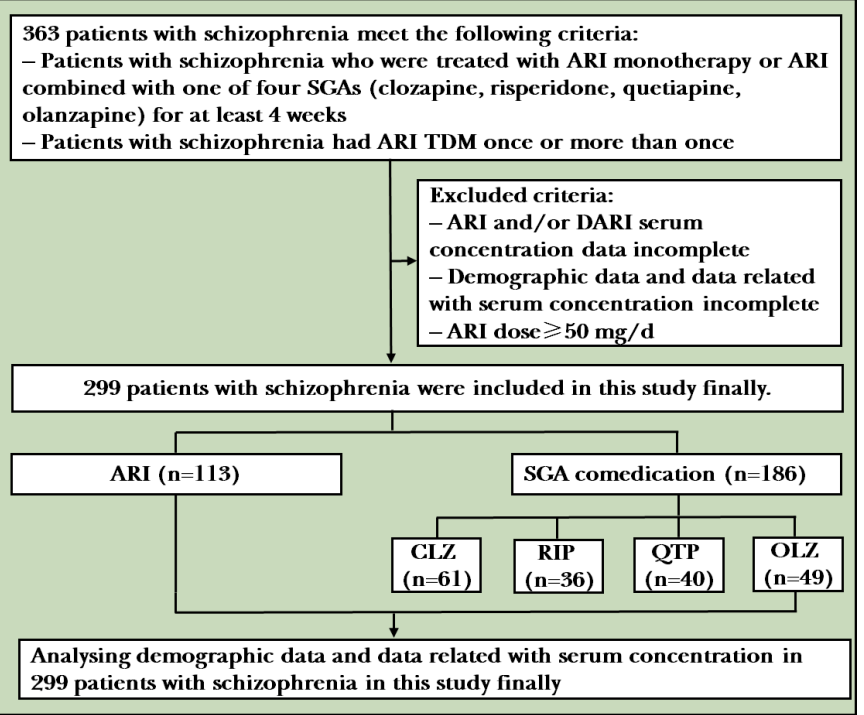

Figure 1 Flowchart of the study. ARI, aripiprazole; CLZ, clozapine; DARI, dehydroaripiprazole; OLZ, olanzapine; QTP, quetiapine; RIP, risperidone; SGA, second-generation antipsychotic; TDM, therapeutic drug monitoring.

monitored at least once during the first 2 months of treatment and then once per month in the hospital.

\section{Sample collection and analysis}

Blood samples $(5 \mathrm{ml})$ were extracted from the cubital vein of patients who had taken ARI for at least 4 weeks between 18:00 and 19:00 (11-12 hours after the last medication dose). Serum concentrations of ARI and DARI were determined with high-performance liquid chromatography (HPLC) using a previously reported method developed in our laboratory. ${ }^{15}$ Samples were analysed with an Agilent 1200 HPLC analyzer using an XDB C18 chromatography column $(4.6 \times 50 \mathrm{~mm}, 1.8 \mu \mathrm{m}$, Agilent; Santa Clara, California, USA) at a detection wavelength of $254 \mathrm{~nm}$. The assay validation data used standard curves for ARI, DARI and the internal standard (purchased from Sigma); the curves were found to be linear, with correlation coefficients of 0.998 and 0.999 , respectively, over a range of $4.0-2000 \mathrm{ng} / \mathrm{ml}$ (ARI) and $4.0-1500 \mathrm{ng} / \mathrm{ml}$ (DARI). A detection limit of $25 \mathrm{ng} / \mathrm{ml}$ for ARI and DARI was achieved, with the relative recovery of $>80.0 \%$ for ARI and $>80.0 \%$ for DARI.

\section{Statistical analysis}

All data were analysed with the Statistical Package for the Social Sciences V.21.0 (SPSS, Chicago, Illinois, USA). Normally distributed data (age and ARI dose) were expressed as mean (SD). Non-normally distributed data (serum ARI, DARI and ARI+DARI concentrations; C:D ratios of ARI, DARI, ARI+DARI and SGA dose) were expressed as the median (IQR: 25-75). Comparisons of the numbers of men and women were conducted using the $\chi^{2}$ test. The independent samples t-test was used to compare two groups/subgroups of normally distributed numerical variables, and a one-way analysis of variance was used to compare multigroups/subgroups of normally 
distributed numerical variables. The Mann-Whitney rank-sum test was used to compare two groups/subgroups of non-normally distributed numerical variables, and the Kruskal-Wallis rank-sum test was used to compare multigroups/subgroups of non-normally distributed numerical variables. Spearman's correlations were used to examine the bivariate associations between any two ARI doses and serum ARI and DARI concentrations in both the ARI and SGA groups. Subsequently, non-normally distributed data (serum ARI concentration and serum DARI concentration) were logarithmically transformed before analysis with multiple linear regression analysis. $\mathrm{P}$ values of $<0.05$ were considered to indicate statistical significance.

\section{RESULTS}

\section{Demographic data}

A total of 299 patients (106 men and 193 women) met the inclusion criteria for this study. Among them, 113 patients received ARI monotherapy ( 43 men and 70 women). The remaining 186 patients (63 men and 123 women) were concomitantly treated with ARI and one other SGA (CLZ, RIP, QTP or OLZ). The ARI and SGA groups accounted for $37.8 \%$ and $62.2 \%$ of the 299 patients included in this study, respectively. The results are shown in table 1.

\section{Comparison of the ARI and SGA groups}

The mean (SD) age of men in the SGA group was significantly higher than that of those in the ARI group (42.3 (12.6) years vs 36.1 (10.4) years, $\mathrm{t}=-4.23, \mathrm{p}<0.001)$. Concerning women, their mean (SD) age in the SGA group was significantly lower than that in the ARI group (43.0 (14.8) years vs 49.7 (18.5) years, $\mathrm{t}=4.30, \mathrm{p}<0.001)$.

The mean (SD) ARI dose in the SGA group was significantly higher than that in the ARI group (21.9 (10.0) $\mathrm{mg} / \mathrm{d}$ vs $20.0(9.3) \mathrm{mg} / \mathrm{d}, \mathrm{t}=-2.63, \mathrm{p}=0.009)$. The mean (SD) ARI dose among women in the SGA group was significantly higher than that among women in the ARI group (22.6 (11.0) $\mathrm{mg} / \mathrm{d}$ vs $19.3(10.1) \mathrm{mg} / \mathrm{d}, \mathrm{t}=-3.43$, $\mathrm{p}=0.001$ ).

There were no significant differences in the serum ARI, DARI or ARI+DARI concentrations across the whole sample or between the male and female samples from the ARI and SGA groups. The median (IQR 25-75) C:D ratios of ARI (10.5 (6.7-15.2) d/L vs $12.2(7.4-19.7) \mathrm{d} / \mathrm{L}$, $\left.\chi^{2}=-3.21, \mathrm{p}=0.001\right)$ and ARI+DARI $(15.7(11.0-22.8) \mathrm{d} / \mathrm{L}$ vs $\left.17.5(10.8-28.4) \mathrm{d} / \mathrm{L}, \chi^{2}=-2.50, \mathrm{p}=0.01\right)$ were both significantly lower in the SGA group than in the ARI group. Similarly, the ratios of the samples of women in the SGA group were lower than those of the women in the ARI group (ARI: 9.7 (6.2-15.1) d/L vs 12.7 (7.3-22.5) $\mathrm{d} / \mathrm{L}, \chi^{2}=-3.59, \mathrm{p}<0.001$; ARI+DARI: $15.1(10.6-22.6) \mathrm{d} / \mathrm{L}$ vs $19.3(11.1-30.7) \mathrm{d} / \mathrm{L}, \chi^{2}=-3.10, \mathrm{p}=0.002$, respectively).

There were no significant differences in the serum ARI, DARI and ARI+DARI concentrations, or the C:D ratios of ARI, DARI and ARI+DARI between the men in the ARI and SGA groups. The results are shown in detail in tables 1-3.

\section{Comparison of the ARI group and SGA subgroups}

Significant differences in age $(\mathrm{F}=15.68, \mathrm{p}<0.001)$ were found between the patients in the ARI group and the four SGA subgroups; this significance was maintained when the men $(\mathrm{F}=10.78, \mathrm{p}<0.001)$ and women $(\mathrm{F}=18.54$, $\mathrm{p}<0.001)$ were considered independently. The mean (SD) ages of the men in the CLZ and OLZ subgroups were significantly higher than those of the men in the ARI group (45.6 (11.2) years vs 36.1 (10.4) years, $\mathrm{t}=-5.81$, $\mathrm{p}<0.001 ; 41.5$ (12.0) years vs 36.1 (10.4) years, $\mathrm{t}=-2.86$, $\mathrm{p}=0.005$, respectively). Women in the RIP, QTP and OLZ subgroups had significantly lower mean (SD) ages than their counterparts in the ARI group (33.9 (10.6) years vs $49.7(18.5)$ years, $\mathrm{t}=7.65, \mathrm{p}<0.001 ; 43.4(12.1)$ years vs $49.7(18.5)$ years, $\mathrm{t}=3.61, \mathrm{p}<0.001 ; 37.1(15.5)$ years vs 49.7 (18.5) years, $\mathrm{t}=5.09, \mathrm{p}<0.001$, respectively).

The mean (SD) ARI dose differed significantly between the SGA subgroups and ARI group $(\mathrm{F}=5.18, \mathrm{p}<0.001)$. The mean (SD) ARI doses were significantly higher in the QTP and OLZ subgroups than in the ARI group (24.2 (10.0) $\mathrm{mg} / \mathrm{d}$ vs $20.0(9.3) \mathrm{mg} / \mathrm{d}, \mathrm{t}=-4.36, \mathrm{p}<0.001 ; 21.7$ (8.6) $\mathrm{mg} / \mathrm{d}$ vs $20.0(9.3) \mathrm{mg} / \mathrm{d}, \mathrm{t}=-2.41, \mathrm{p}=0.02$, respectively). Women in the QTP and OLZ subgroups received significantly higher mean (SD) ARI doses than women in the ARI group (24.5 (10.3) mg/d vs $19.3(10.1) \mathrm{mg} / \mathrm{d}$, $\mathrm{t}=-4.36, \mathrm{p}<0.001 ; 22.7(9.0) \mathrm{mg} / \mathrm{d}$ vs $19.3(10.1) \mathrm{mg} / \mathrm{d}$, $\mathrm{t}=-2.55, \mathrm{p}=0.01$, respectively).

There were no significant differences in the median serum concentrations of ARI, DARI and ARI+DARI between the four SGA subgroups and the ARI group. This finding was the same for both men and women.

There were significant differences in the median C:D ratios of ARI $\left(\chi^{2}=18.24, p=0.001\right)$, DARI $\left(\chi^{2}=10.65\right.$, $\mathrm{p}=0.03)$ and ARI+DARI $\left(\chi^{2}=15.38, \mathrm{p}=0.004\right)$ between the four SGA subgroups and the ARI group. Among the four SGA subgroups, patients in the QTP subgroup as a whole had significantly different C:D ratios of ARI (9.4 (7.2-11.8) d/L vs $12.2(7.4-19.7)$ d/L, $Z=-4.12$, $\mathrm{p}<0.001)$ and ARI+DARI $(14.2(10.9-18.2) \mathrm{d} / \mathrm{L}$ vs 17.5 $(10.8-28.4) \mathrm{d} / \mathrm{L}, \mathrm{Z}=-3.62, \mathrm{p}<0.001)$ than those in the ARI group. Moreover, the C:D ratios of ARI (9.5 (7.2-11.8) $\mathrm{d} / \mathrm{L}$ vs 12.7 (7.3-22.5) d/L, $\mathrm{Z}=-3.96, \mathrm{p}<0.001)$, DARI (4.9 $(3.2-6.5) \mathrm{d} / \mathrm{L}$ vs $5.6(3.5-9.0) \mathrm{d} / \mathrm{L}, \mathrm{Z}=-2.22, \mathrm{p}=0.03)$ and ARI+DARI (14.7 (11.1-18.1) d/L vs 19.3 (11.1-30.7) d/L, $\mathrm{Z}=-3.75, \mathrm{p}<0.001$ ) were significantly different between women in the QTP subgroup and women in the ARI group. However, there was no significant difference in the median C:D ratios between the men in the four SGA subgroups and their counterparts in the ARI group. Most results are shown in tables $1-3$ and figures 2 and 3 .

\section{Spearman's correlation analysis}

Several significant correlations between ARI dose and the serum concentrations of ARI and DARI in both the ARI and SGA groups were identified. In the ARI group, the strongest correlation was between the serum concentrations of ARI and DARI $\left(\mathrm{r}_{\mathrm{s}}=0.70, \mathrm{p}<0.001\right)$; a similar result 


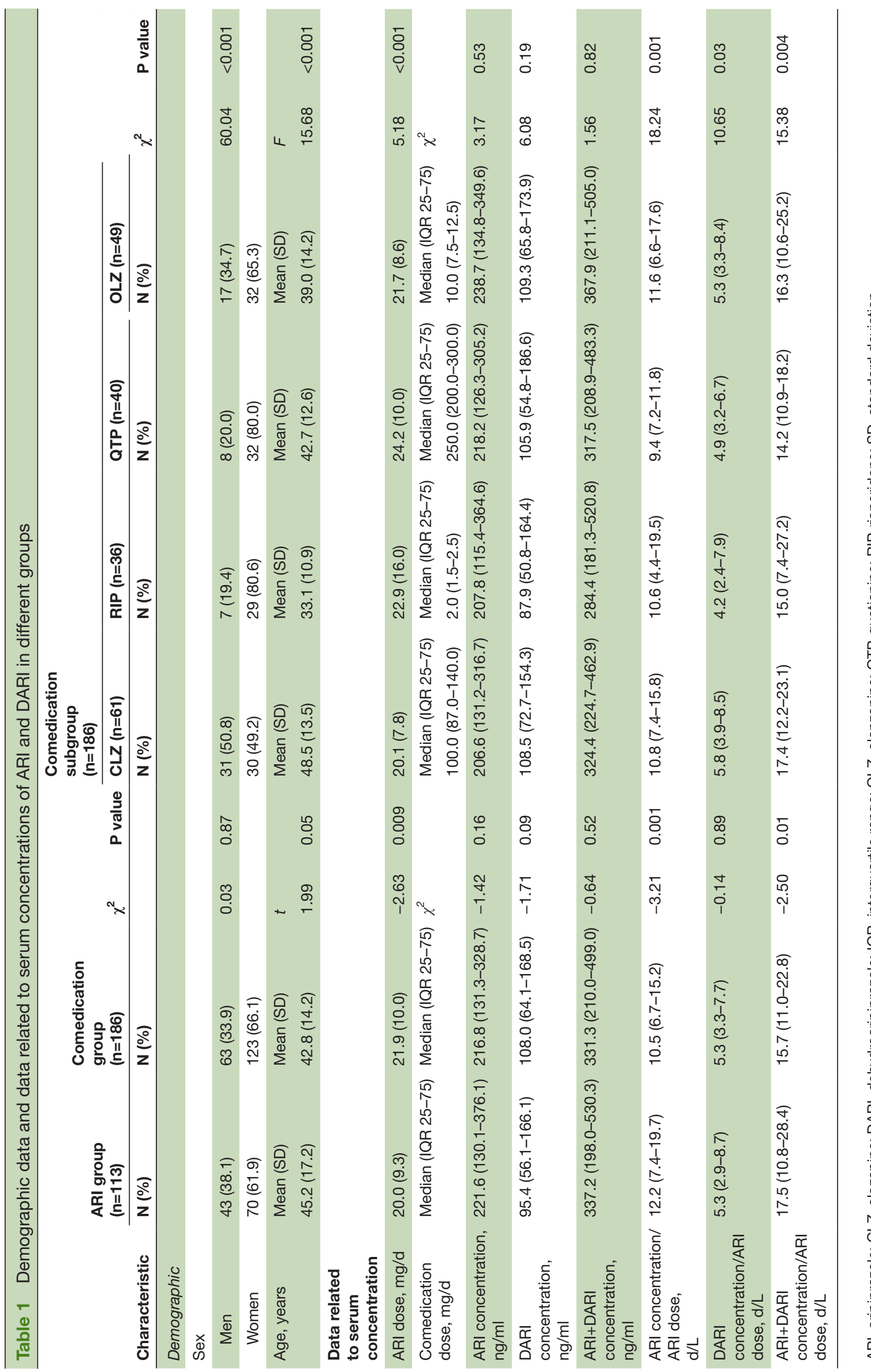




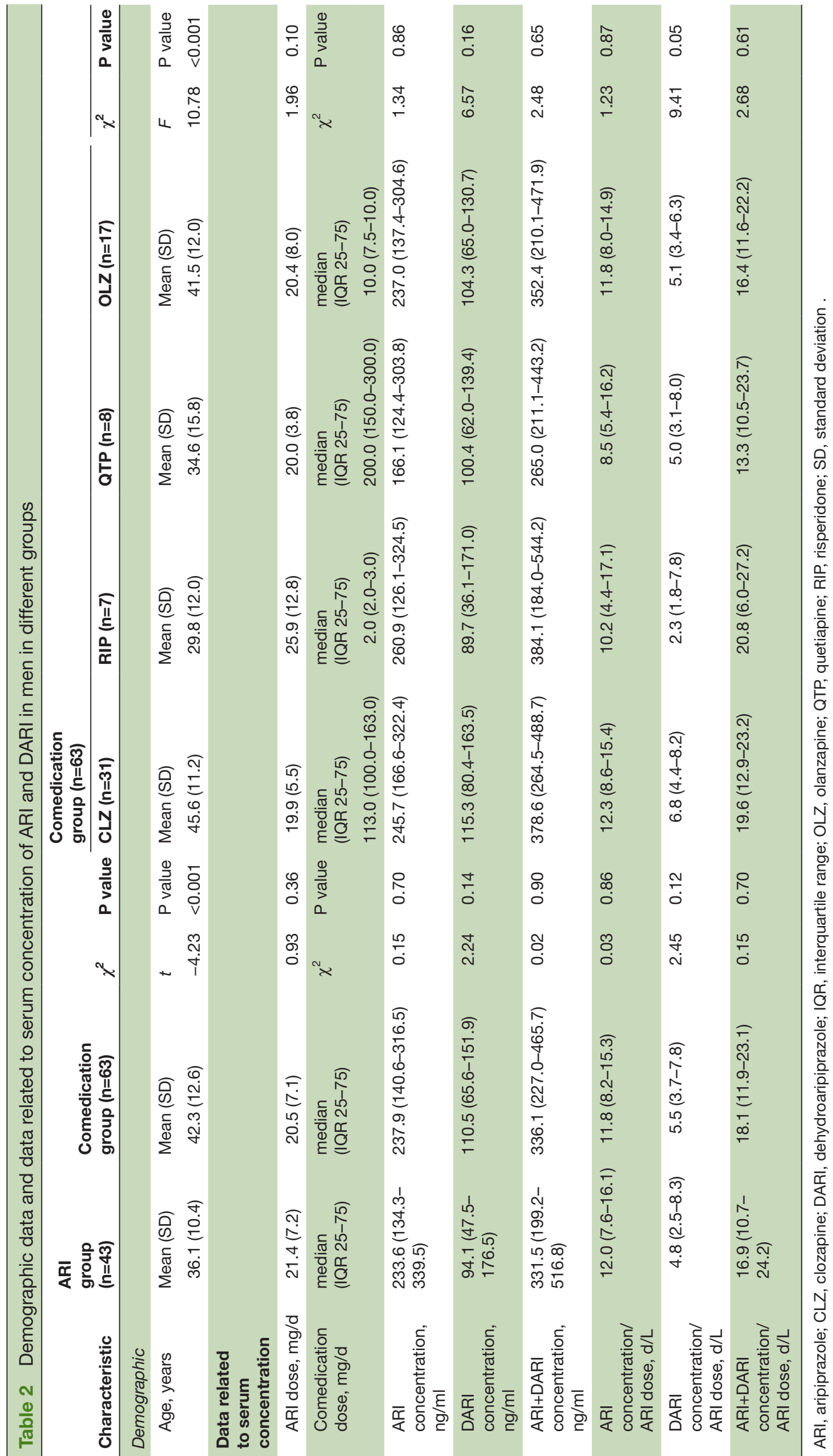








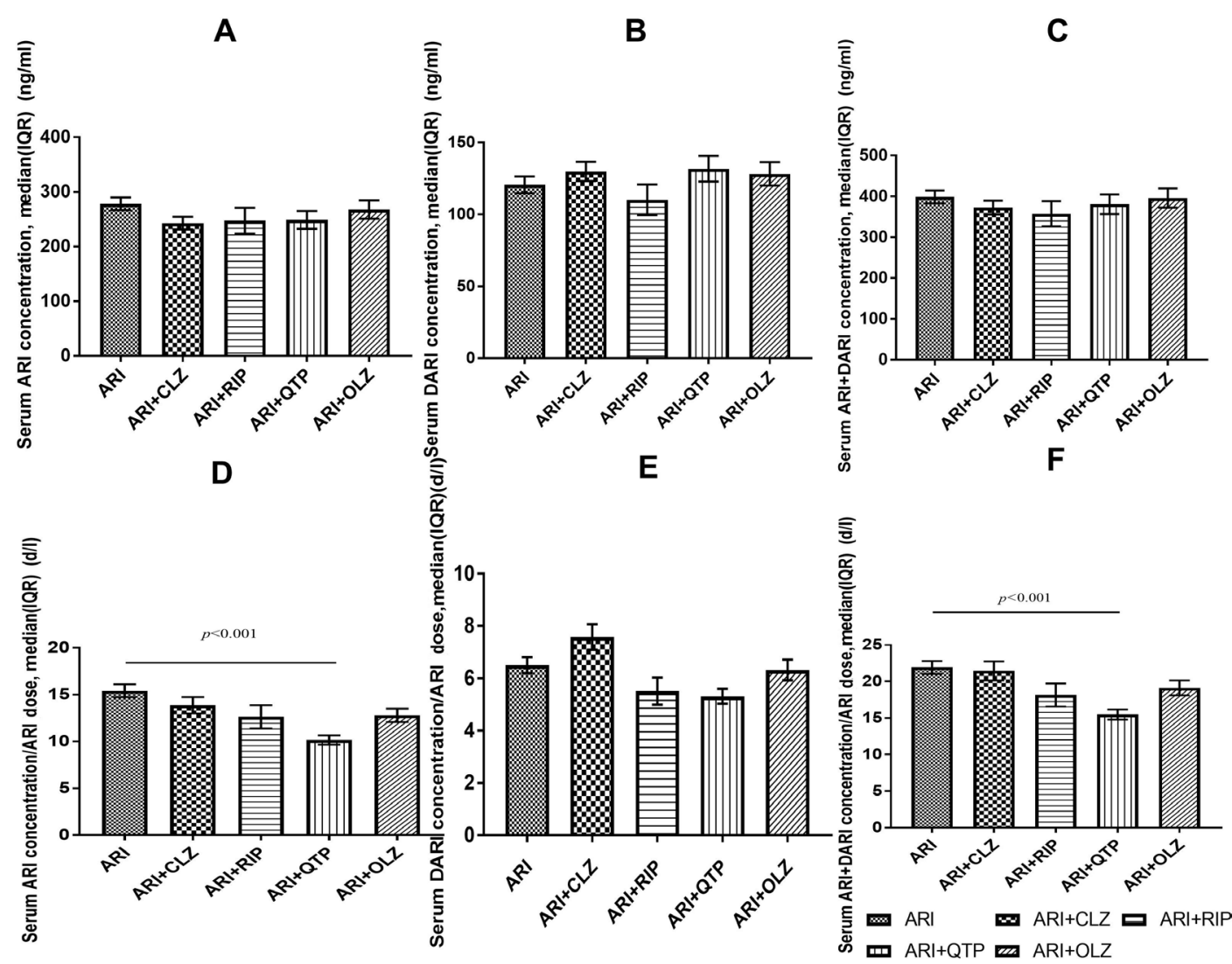

Figure 2 Serum ARI, DARI and ARI+DARI concentrations and the C:D ratios of ARI, DARI and ARI +DARI in patients with schizophrenia. ARI, aripiprazole; CLZ, clozapine; DARI, dehydroaripiprazole; RIP, risperidone; OLZ, olanzapine; QTP, quetiapine.

was found in the SGA group $\left(\mathrm{r}_{\mathrm{s}}=0.72, \mathrm{p}<0.001\right)$. The results are shown in table 4 .

\section{Multiple linear regression analysis}

Using stepwise regression analysis, two regression equations were defined to describe the effects of independent variables, including sex (X1), age (X2), ARI dose (X3) and SGA comedication (X4), on serum ARI and DARI concentrations.

The serum ARI concentration was set as the dependent factor $(\mathrm{Y})$. The regression equation is as follows: serum ARI concentration $(\mathrm{Y})=212.31-0.88$ age +10.32 ARI dose - 39.07 SGA comedication $(\mathrm{F}=19.99, \mathrm{p}<0.001$; constant: $\mathrm{t}=6.44, \mathrm{p}<0.001$; age: $\mathrm{t}=-2.06, \mathrm{p}=0.04 ;$ ARI dose: $\mathrm{t}=7.79$, $\mathrm{p}<0.001$; SGA comedication: $\mathrm{t}=-2.99, \mathrm{p}=0.003)$.

The results showed that age, ARI dose and SGA comedication significantly affected serum ARI concentration, while sex did not. Specifically, Y was positively correlated with ARI dose and negatively correlated with age and SGA comedication. These findings indicate that higher ARI doses and/or younger ages are associated with higher serum ARI concentration, while comedication with SGA is associated with lower serum ARI concentration. The results are shown in table 5 .

The serum DARI concentration was set as the dependent factor $(\mathrm{Y})$. The regression equation is as follows: serum DARI concentration $(\mathrm{Y})=83.72+5.26$ ARI dose
$(\mathrm{F}=16.30, \mathrm{p}<0.001 ;$ constant: $\mathrm{t}=4.82, \mathrm{p}<0.001 ;$ ARI dose: $\mathrm{t}=7.67, \mathrm{p}<0.001$ ).

The ARI dose was the only factor found to affect serum DARI concentration. Age and SGA comedication did not significantly affect serum DARI concentration. These findings indicate that higher ARI doses are associated with higher serum DARI concentration. The results are shown in table 5 .

\section{DISCUSSION}

\section{Main findings}

Schizophrenia is a complex, multidimensional disorder, whose optimal treatment may require the careful individualisation of appropriate drug combinations. ${ }^{16-18}$ Many studies have shown a trend towards the parallel use of ARI along with one or more SGAs to treat patients with schizophrenia. ${ }^{1718}$ In our study, more than $60 \%$ of the inpatients who were prescribed ARI also received one of four SGAs. With the increasing use of ARI combination with SGA, the potential for drug-drug interactions is becoming an important consideration in the treatment of patients with schizophrenia. While SGAs appear neither to induce nor inhibit the enzymes involved in the metabolism of ARI, the metabolism of ARI can be affected by other drugs that use the same metabolic pathways. 

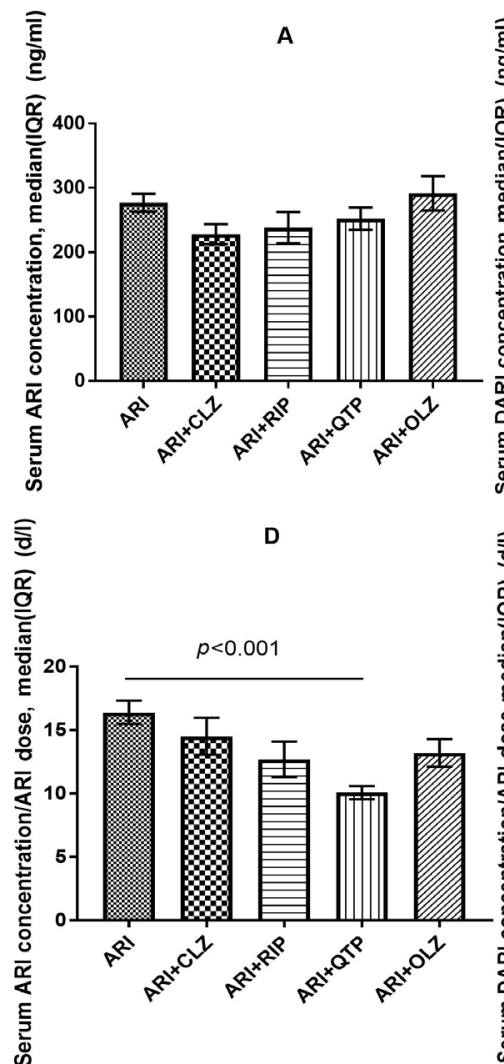
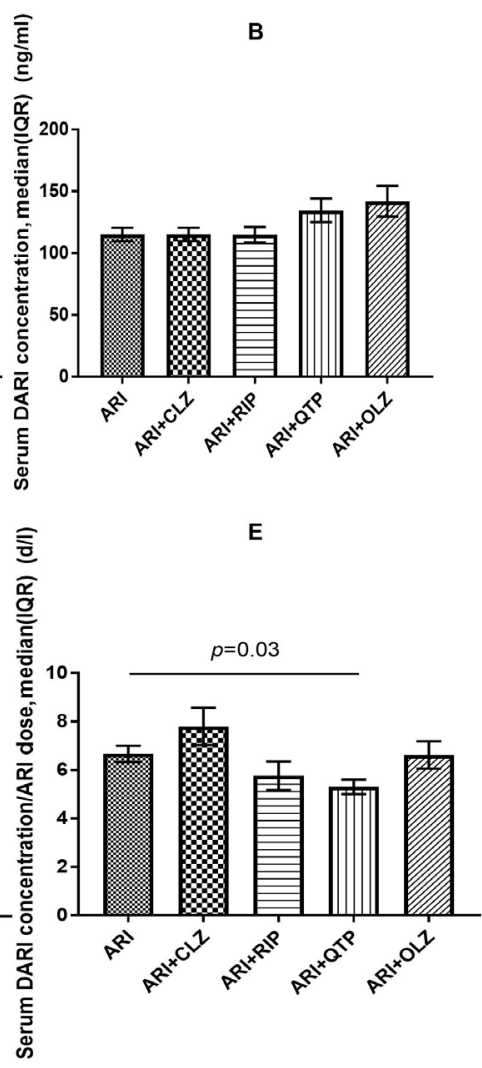
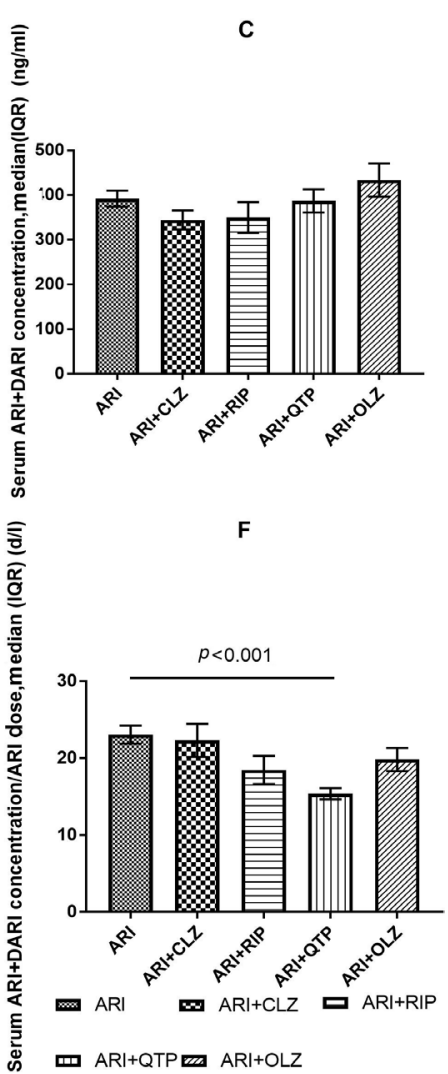

Figure 3 Serum ARI, DARI and ARI+DARI concentrations and the C:D ratios of ARI, DARI and ARI+DARI in female patients with schizophrenia. ARI, aripiprazole; CLZ, clozapine; DARI, dehydroaripiprazole; OLZ, olanzapine; QTP, quetiapine; RIP, risperidone.

There are several factors that contribute to ARI comedication with SGAs. First, patients can be referred to hospitals owing to their being therapy-refractory and the lack of the efficacy of a previously received monotherapy. ${ }^{17-20}$ Second, ARI comedication with SGA may also reflect poor prescribing practices caused by requests from nurses for more drugs or clinicians' scepticism towards and incomplete confidence in ARI monotherapy. ${ }^{17}$ Third, ARI comedication with SGA may also reflect rational prescription in terms of the treatment of symptoms and comorbid conditions or the reduction of the risk of adverse drug reactions associated with high doses of one compound. ${ }^{18-20}$ Furthermore, increasing ARI comedication with SGA in the treatment of schizophrenia has been associated with diminished adverse drug reactions and improved indicators of beneficial patient outcomes. ${ }^{17-20}$

As expected, we found that the serum concentrations of ARI, DARI and ARI+DARI were not influenced by SGAs as a whole or by any of the four subgroups of SGA comedication when analysed with the Mann-Whitney U rank-sum test and the Kruskal-Wallis rank-sum test. This is consistent with the observations of previous studies. ARI is extensively metabolised by the cytochrome (CYP) P450s, CYP3A4 and CYP2D6, whereas the other four SGAs in this study-CLZ, RIP, QTP and OLZ-are primarily metabolised by CYP enzymes and are neither inhibitors nor inducers of ARI. ${ }^{2122}$ The findings of multiple studies thus indicate that the four SGAs do not significantly affect the

Table 4 Spearman's correlation analysis of ARI dose and serum concentrations of ARI and DARI

\begin{tabular}{|c|c|c|c|c|c|c|}
\hline \multirow[b]{2}{*}{ Index } & \multicolumn{3}{|c|}{ In ARI group } & \multicolumn{3}{|c|}{ In SGA comedication group } \\
\hline & ARI dose & $\begin{array}{l}\text { ARI } \\
\text { concentration }\end{array}$ & $\begin{array}{l}\text { DARI } \\
\text { concentration }\end{array}$ & ARI dose & $\begin{array}{l}\text { ARI } \\
\text { concentration }\end{array}$ & $\begin{array}{l}\text { DARI } \\
\text { concentration }\end{array}$ \\
\hline $\mathrm{ARI}$ concentration & $r_{\mathrm{s}}=0.27^{\star}$ & - & $r_{\mathrm{s}}=0.70^{\star}$ & $r_{\mathrm{s}}=0.45^{\star}$ & - & $r_{\mathrm{s}}=0.72^{*}$ \\
\hline DARI concentration & $r_{s}=0.31^{*}$ & $r_{s}=0.70^{*}$ & - & $r_{s}=0.41^{*}$ & $r_{\mathrm{s}}=0.72^{*}$ & - \\
\hline
\end{tabular}

${ }^{*} \mathrm{P}<0.001$.

$\mathrm{ARI}$, aripiprazole; DARI, dehydroaripiprazole. 
Table 5 Factors ${ }^{\star}$ related to serum ARI and DARI concentrations in patients with schizophrenia as identified with stepwise regression analysis $(n=299)$

\begin{tabular}{|c|c|c|c|c|c|c|c|}
\hline \multirow{2}{*}{$\begin{array}{l}\text { Index } \\
\text { Factor }\end{array}$} & \multicolumn{3}{|c|}{ In serum ARI concentration } & \multicolumn{4}{|c|}{ In serum DARI concentration } \\
\hline & Coefficient & $t$ & $P$ value & Factor & Coefficient & $t$ & $P$ value \\
\hline Constant & 212.31 & 6.44 & $<0.001$ & Constant & 83.72 & 4.82 & $<0.001$ \\
\hline ARI dose & 10.32 & 7.79 & $<0.001$ & & & & \\
\hline Comedication & -39.07 & -2.99 & 0.003 & & & & \\
\hline
\end{tabular}

*Serum ARI concentration: adjusted $R$ squares of the equation is $0.091(F=19.99, p<0.001)$. Serum DARI concentration: adjusted $R$ squares of the equation is 0.075 ( $F=16.30, p<0.001)$.

$\mathrm{ARI}$, aripiprazole; DARI, dehydroaripiprazole.

activity of ARI's CYP isoenzymes and consequently have no significant effects on the serum concentrations of ARI, DARI and ARI+DARI. ${ }^{21-29}$ In other words, the four SGAs in this study are unlikely to interfere with the biotransformation of concomitant ARI under typical circumstances.

However, there are still some contradictory results in our study. Lower C:D ratios of ARI and ARI+DARI were observed in patients who were taking SGA comedication, whereas the C:D ratio of DARI remained unchanged. Of the four SGA subgroups, only QTP significantly affected the $\mathrm{C}: \mathrm{D}$ ratios of ARI $(\mathrm{Z}=-4.12, \mathrm{p}<0.001)$ and $\mathrm{ARI}+\mathrm{DARI}$ $(\mathrm{Z}=-3.62, \mathrm{p}<0.001)$ when compared with the ARI group as a whole; when the comparison was restricted to women, the C:D ratios of ARI, DARI and ARI+DARI ( $\mathrm{Z}=-3.96$, $\mathrm{p}<0.001 ; \mathrm{Z}=-2.22, \mathrm{p}=0.03 ; \mathrm{Z}=-3.75, \mathrm{p}<0.001)$ significantly differed between the QTP subgroup and the ARI group.

While other evidence suggests that SGAs may interact with ARI, some of these interactions may be reported only analytically or reflect pharmacokinetic observations of doubtful practical relevance, which can result in reduced effectiveness of ARI or increased risk of adverse events. ${ }^{1215}$ Combining SGA with ARI to reduce clinically significant risks of drug-drug interactions is a more reliable treatment option for patients in whom serum ARI levels may fluctuate. Therefore, the use of SGA combinations with low potential for drug-drug interactions is desirable, especially for older patients who are more likely to take many medications.

The effect of comedication with QTP on the pharmacokinetics of ARI has rarely been investigated and thus remains unclear. ${ }^{15}$ Ren et al found that the combination of QTP significantly reduced the C:D ratio of ARI and ARI+DARI in Chinese inpatients with mental illness by $30.1 \%(p=0.02)$ and $24.2 \%(p=0.02)$, respectively. Consistent with the result of this study, Ren et al also observed no significant effect of comedication with QTP on the C:D ratio of DARI. In other words, previous findings may implicate QTP in the metabolism of ARI to metabolites other than DARI. ${ }^{15}$

QTP, a dibenzothiazepine derivative, is mainly metabolised by CYP2D6 and CYP3A4, whereas ARI is extensively metabolised by CYP3A4 and CYP2D6 through three biotransformation pathways: dehydrogenation, hydroxylation and N-dealkylation. CYP3A4 and CYP2D6 are involved in dehydrogenation and hydroxylation, and CYP3A4 is involved in N-dealkylation. The coadministration of QTP and ARI of the CYP3A4 and CYP2D6 enzymes may account for the involvement of QTP in the metabolism of ARI to metabolites other than DARI. Moreover, as some cases have documented a change in plasma concentrations of ARI following its coadministration with QTP, decreases in dosages may then be required to avoid possible adverse effects or therapeutic failure. ${ }^{24}$ These two reasons may partly explain why the C:D ratio of ARI and ARI+DARI significantly decreased while the serum concentration of ARI and ARI+DARI remain unchanged in the QTP comedication group. Furthermore, factors such as sex, age, body mass index, smoking amount, comorbidity and administering medication other than psychiatric drugs may also affect the serum concentrations. As description of ARI-QTP interaction patterns is needed for clinicians, ${ }^{30}$ more studies are needed to explore the mechanism of this interaction.

We did not observe any significant influence of the coadministration of CLZ and ARI on serum ARI, DARI and ARI+DARI concentrations or the dose-adjusted index. These findings are highly consistent with other reports. ${ }^{16} 172526$ CLZ is a dibenzodiazepine derivative that has complex hepatic metabolism in humans. In vivo and in vitro studies suggest that multiple CYP isoforms, mainly CYP1A2 and to a lesser extent CYP3A4, CYP2D6 and CYP2C19, are involved in the biotransformation of CLZ. ${ }^{16} 172526$ ARI is extensively metabolised by CYP3A4 and CYP2D6, and many studies have suggested no drug interaction between CLZ and ARI. ${ }^{17}$

We also observed no significant influence of the coadministration of RIP and ARI on serum ARI, DARI and ARI+DARI concentrations or dose-adjusted index. These observations are similar to those of previous studies. However, Waade $e t a \vec{l}^{0}$ found a lower median C:D ratio of DARI when ARI was coadministered with RIP injections, whereas no significant influence was observed with RIP tablets. Therefore, the results observed in our study are consistent with Waade's investigation of RIP tablets but are inconsistent with RIP injections; hence, the different effects of RIP coadministration on ARI pharmacokinetics could be due to differences in potential ARI-RIP interactions between RIP injections and tablets. 
In agreement with the literature, we found that OLZ had no impact on ARI metabolism. Uridine diphosphateglucuronosyltransferase (UGT) enzymes, including UGT1A4, are involved in the metabolism of OLZ. A pharmacokinetic interaction between OLZ and ARI is unexpected because OLZ is not metabolised by ARI enzymes or bound to plasma proteins. ${ }^{16}$ However, Waade et al showed that OLZ had significant impact on the ARI metabolic ratio (serum DARI concentration: serum ARI concentration), which was approximately $20 \%$ lower than in controls. Some researchers speculate that an unelucidated ARI metabolic pathway involving UGT enzymes may be involved in the observed minor interaction between ARI and OLZ. ${ }^{30}$ Therefore, more studies are warranted to explore and confirm this speculation.

The equations used for the multiple linear regression analysis showed that SGA comedication, when administered in the recommended dose range, influenced only the pharmacokinetics of ARI. Age and ARI dose were also observed to exert an effect. These findings are consistent with the presently observed effect of SGA comedication as a whole on the C:D ratio of ARI and ARI+DARI. Thus, this study provides information that can be used to inform clinicians of the optimal ARI dose and need for comedication with SGA for the treatment of Chinese patients with schizophrenia.

However, according to these equations, the effect of SGA comedication on the serum concentration of ARI was minimal. For example, a 30 -year-old patient receiving ARI monotherapy (ARI dose: $20.0 \mathrm{mg} / \mathrm{d}$ ) was predicted to have a serum ARI concentration of $392.3 \mathrm{ng} / \mathrm{ml}$ and a serum DARI concentration of $188.9 \mathrm{ng} / \mathrm{ml}$, whereas a 30-year-old patient receiving ARI (ARI dose: $20 \mathrm{mg} / \mathrm{d}$ ) with SGA comedication was predicted to have a serum ARI concentration of $353.2 \mathrm{ng} / \mathrm{ml}$ and a serum DARI concentration of $188.9 \mathrm{ng} / \mathrm{ml}$. The differences in serum ARI and DARI concentrations between patients treated with or without SGA comedication were only $39.1 \mathrm{ng} /$ $\mathrm{ml}$ and $0 \mathrm{ng} / \mathrm{ml}$, respectively. Although the effect of SGA comedication on serum ARI concentration was statistically significant, it is unlikely to be clinically significant due to the relatively broad therapeutic concentrations of ARI $(150-300 \mathrm{ng} / \mathrm{ml}) .{ }^{11} 3132$ Despite the statistical significance, the two equations explain only $9.1 \%$ and $7.5 \%$ of the variance in serum ARI and DARI concentrations, respectively. Such ARI doses often require adjustment according to the symptoms and clinical indicators of different individuals. Furthermore, the observed and predicted data were based on a patient population that only comprised Chinese inpatients $(n=299)$, and further investigations are required to investigate the validity of these predictions in other populations.

In this study, we retrospectively measured the serum concentrations of ARI and DARI in 299 Chinese inpatients with schizophrenia with respect to comedications with four SGAs. Our results in patients on ARI monotherapy (ARI dose: 20.0 (9.3) mg/d; serum ARI concentration: 221.6 (130.1-376.1) ng/ml; serum DARI concentration:
$95.4(56.1-166.1) \mathrm{ng} / \mathrm{ml})$ are highly similar to the results of Nakamura's study in Japanese patients (ARI dose: 22.0 (4.6) $\mathrm{mg} / \mathrm{d}$; serum ARI concentration: 273.5 (113.3) $\mathrm{ng} / \mathrm{ml}$; serum DARI concentration: $123.3(44.0) \mathrm{ng} / \mathrm{ml}$, respectively). ${ }^{31}$ The ARI dose in our study (20.0 (9.3) $\mathrm{mg} / \mathrm{d}$ ) was significantly lower than that in studies by Citrome et $a l^{2829}(30 \mathrm{mg} / \mathrm{d})$ in US patients with schizophrenia. The serum concentrations of ARI and DARI in our study and studies by Citrome $e t a l^{28}{ }^{29}$ (ARI: 236.7 (82.1) $\mathrm{ng} / \mathrm{ml}$; DARI: 102.1 (25.6) $\mathrm{ng} / \mathrm{ml}$ ) were similar. The observed lower ARI dose with similar serum concentrations of ARI and DARI in our study may be explained by the fact that CYP2D6*10 allele is prevalent in Chinese and Japanese populations and plays an important role in controlling the serum concentrations of ARI and DARI in Asian individuals. ${ }^{15} 2031$ The CYP2D6*10 allele causes decreased CYP2D6 activity in both ARI and DARI metabolism. This may explain why the same ARI dose caused higher serum concentrations of ARI and DARI in Asian individuals with CYP2D6*10 allele relative to their Western counterparts with other CYP2D6 alleles.

In many studies, patients were dosed according to clinical need; all mean ARI doses were within the range of $15-20 \mathrm{mg} / \mathrm{d}$, and the majority of serum ARI levels were just above the upper limit of the suggested range of $150-210 \mathrm{ng} / \mathrm{ml}$. Kirschbaum et al ${ }^{1132}$ suggested that the target serum concentration range of ARI for efficacy was $146-254 \mathrm{ng} / \mathrm{ml}$. A wider efficacy serum ARI concentration range $(150-300 \mathrm{ng} / \mathrm{ml})$ is suggested by classic opinion. The mean serum ARI concentrations in our study were 221.6 (130.1-376.1) $\mathrm{ng} / \mathrm{ml}$ in the ARI group and 216.8 (131.3-328.7) $\mathrm{ng} / \mathrm{ml}$ in the SGA group, which are both very similar to the concentrations used in studies by Kirschbaum et al (219 (105-549) ng/L), ${ }^{11} 32$ Mallikaarjun et al $(98-452 \mathrm{ng} / \mathrm{ml}),{ }^{33}$ and Bachmann et al (142 (123) $\mathrm{ng} / \mathrm{ml}) .^{34}$ The serum ARI concentration range in our study falls below the ranges reported by Zuo et al (457.7 $(115.8) \mathrm{ng} / \mathrm{ml}) .^{35}$ These results indicated that the ARI dose in our study was relatively safe and effective. As patients were dosed freely according to clinical decision, it may be assumed that doses were titrated for optimal efficacy and the avoidance of adverse effects, which would provide some support for the efficacy and adverse effects of serum concentration ranges.

Of the results yielded by our regression analyses of the three factors (age, ARI dose, SGA comedication) affecting the serum concentration of ARI, only the ARI dose on DARI partly agreed with prior findings. ${ }^{32-34}$ The discrepancy with the findings of other studies can possibly be explained by the different genotypes of ARI-metabolising enzymes CYP2D6 or other factors of the patient populations. However, this cannot be confirmed as we were unable to genotype our study sample. Other factors, such as body mass index, smoking, comorbidity and administering medication other than psychiatric drugs contributed to the differences as well. Sex was believed by Molden to have no relationship with the serum concentration of $\mathrm{ARI}^{36}$; this is consistent with our findings that sex has no 
effect on both serum ARI and DARI concentrations in the two equations.

Spearman's correlation analysis showed the strongest correlation between the serum concentrations of ARI and DARI. These findings are in line with those of other studies, which showed a clear relationship between the serum concentrations of ARI and DARI. ${ }^{10}{ }^{12}$ In addition, evidence shows a strong linear correlation between ARI dose and serum concentration of ARI and a similarly robust correlation between ARI dose and serum concentration of DARI. This could explain why ARI dose was the only factor that affected the serum concentrations of both ARI and DARI in our research.

\section{Limitations}

There were several limitations in this study, including its retrospective study design as well as differences in the sample sizes and ratios of men to women between the groups. In addition, the severity of schizophrenia, clinical profiles and side effects were not included in the analysis. Although the number of patients included was large, and serum concentrations were available, greater statistical power may improve the strength of these findings. Future studies can improve on the design of the present investigation by employing a prospective study design and analysing other factors that may influence serum ARI and DARI concentrations, such as CYP polymorphisms, body mass index, smoking, comorbidity and administering medication other than psychiatric drugs. In addition, the number of samples in each group should be approximately the same. Future studies should also measure patient outcomes. This would inform research on the impact factors of serum ARI and DARI concentrations.

\section{Implications}

ARI is a relatively new antipsychotic agent, and there is limited clinical information available regarding any relevant drug-drug interactions. Monitoring the serum levels of ARI and DARI has been shown to facilitate the assessment of metabolic status, prevent toxicity and optimise doses in clinic.

This study found that comedication with SGAs resulted in lower C:D ratios of ARI and ARI+DARI compared with ARI monotherapy, and comedication with QTP resulted in lower C:D ratios of ARI and ARI+DARI than did ARI monotherapy. The regression equations defined in this study provide a useful method by which clinicians can more accurately individualise ARI dose titration schedule when comedicating with SGA. This will help to avoid the cost and inconvenience of frequently collecting blood samples to assess serum ARI concentrations.

Despite this statistical significance of our findings, whether the presently observed effect has clinical significance requires exploration by further research. Nevertheless, the TDM of ARI and its metabolite should be emphasised for patients undergoing combination therapy, and ARI doses should be adjusted to achieve the best and safest therapeutic effect when comedicating with SGAs, especially QTP.

Contributors $\mathrm{PJ}$ and $\mathrm{CZ}$ participated in the conception and design of the study. PJ, XJS, JJR, HML and ZGL collected the data. PJ and JWL processed the data. $P J$ and XYF performed the statistical analyses. All authors interpreted the results. PJ drafted the manuscript, and all authors revised the manuscript critically for important intellectual content. The authors are responsible for the paper's data.

Funding This work was supported by the Shanghai Natural Science Foundation (15ZR1435300); Natural Science and Technology Foundation of Shanghai Jiao Tong University School of Medicine (14XJ10080); Shanghai Key Laboratory of Psychotic Disorders (13dz2260500); Teacher Train and Progress Project of Shanghai Jiao Tong University School of Medicine (JFXM201808); Shanghai Mental Health Center Project (2018-YJ-16); China Hospital Development Research Institute Hospital Management Construction Project of Shanghai Jiao Tong University (CHDI2018-A-23); Young and Middle-aged Teachers Study Abroad Program of Shanghai Jiao Tong University School of Medicine; and Wang Kuancheng Medical Award Fund Project of Shanghai Jiao Tong University.

Competing interests None declared.

Patient consent for publication Not required.

Ethics approval Obtained (2007-20). This study was approved by the Institutional Ethics Committee of the Shanghai Mental Health Center (IORG Number: IORG0002202, FWA Number: FWA00003065). The Institutional Ethics Committee of the Shanghai Mental Health Center also approved the consent procedure.

Provenance and peer review Not commissioned; externally peer reviewed.

Data availability statement All data relevant to the study are included in the article or uploaded as supplementary information. We state that all data relevant to the study are included in the article or uploaded as supplementary information.

Open access This is an open access article distributed in accordance with the Creative Commons Attribution Non Commercial (CC BY-NC 4.0) license, which permits others to distribute, remix, adapt, build upon this work non-commercially, and license their derivative works on different terms, provided the original work is properly cited, appropriate credit is given, any changes made indicated, and the use is non-commercial. See: http://creativecommons.org/licenses/by-nc/4.0/.

ORCID iD

Xiujia Sun http://orcid.org/0000-0002-7329-7314

\section{REFERENCES}

1 Suzuki T, Mihara K, Nakamura A, et al. Effects of genetic polymorphisms of CYP2D6, CYP3A5, and ABCB1 on the steadystate plasma concentrations of aripiprazole and its active metabolite, dehydroaripiprazole, in Japanese patients with schizophrenia. Ther Drug Monit 2014;36:651-5.

2 Boyd KN, Mailman RB. Dopamine receptor signaling and current and future antipsychotic drugs. Handb Exp Pharmacol 2012;212:53-86.

3 Khanna P, Suo T, Komossa K, et al. Aripiprazole versus other atypical antipsychotics for schizophrenia. Cochrane Database Syst Rev 2014;18:CD006569.

4 McCutcheon R, Beck K, D'Ambrosio E, et al. Antipsychotic plasma levels in the assessment of poor treatment response in schizophrenia. Acta Psychiatr Scand 2018;137:39-46.

5 Mailman RB, Murthy V. Third generation antipsychotic drugs: partial agonism or receptor functional selectivity? Curr Pharm Des 2010;16:488-501.

6 Nagai G, Mihara K, Nakamura A, et al. Prolactin concentrations during aripiprazole treatment in relation to sex, plasma drugs concentrations and genetic polymorphisms of dopamine D2 receptor and cytochrome P450 2D6 in Japanese patients with schizophrenia. Psychiatry Clin Neurosci 2012;66:518-24.

7 Khanna P, Komossa K, Rummel-Kluge C, et al. Aripiprazole versus other atypical antipsychotics for schizophrenia. Cochrane Database Syst Rev 2013;2:CD006569.

8 Grinevich VP, Papke RL, Lippiello PM, et al. Atypical antipsychotics as noncompetitive inhibitors of alpha4beta2 and alpha7 neuronal nicotinic receptors. Neuropharmacology 2009;57:183-91.

9 Cipriani $\mathrm{A}$, Accordini $\mathrm{S}$, Nosè $\mathrm{M}$, et al. Aripiprazole versus haloperidol in combination with clozapine for treatment-resistant schizophrenia: a 12-month, randomized, naturalistic trial. J Clin Psychopharmacol 2013;33:533-7. 
10 Barber S, Olotu U, Corsi M, et al. Clozapine combined with different antipsychotic drugs for treatment-resistant schizophrenia. Cochrane Database Syst Rev 2017;3:CD006324.

11 Kirschbaum KM, Müller MJ, Malevani J, et al. Serum levels of aripiprazole and dehydroaripiprazole, clinical response and side effects. World J Biol Psychiatry 2008;9:212-8.

12 Kubo M, Koue T, Inaba A, et al. Influence of itraconazole coadministration and CYP2D6 genotype on the pharmacokinetics of the new antipsychotic aripiprazole. Drug Metab Pharmacokinet 2005;20:55-64.

13 Hendset M, Hermann M, Lunde H, et al. Impact of the CYP2D6 genotype on steady-state serum concentrations of aripiprazole and dehydroaripiprazole. Eur J Clin Pharmacol 2007;63:1147-51.

$14 \mathrm{Kim} \mathrm{J-R,} \mathrm{Seo} \mathrm{H-B,} \mathrm{Cho} \mathrm{J-Y,} \mathrm{et} \mathrm{al.} \mathrm{Population} \mathrm{pharmacokinetic}$ modelling of aripiprazole and its active metabolite, dehydroaripiprazole, in psychiatric patients. Br J Clin Pharmacol 2008:66:802-10.

15 Ren J, Lin Z, Liu H, et al. Effect of drug combination on blood concentration of aripiprazole and its metabolite. China Pharmacy 2011;22:3968-70.

16 Jiang $\mathrm{P}$, Liu H, Ren J, et al. Detection of plasma clozapine, Norclozapine concentration in inpatients of comedication with psychosis disorder. Acad J Sec Mil Med Univ 2013;34:759-63.

17 Jiang P, Lin Z, Jin Y, et al. Effect of clonazepam co-administered with clozapine on the serum clozapine and Norclozapine concentration of patients with schizophrenia: a retrospective survey. Shanghai Arch Psychiatry 2016;28:318-25

18 Juncal-Ruiz M, Riesco-Dávila L, Ortiz-García de la Foz V, et al. Comparison of the anti-inflammatory effect of aripiprazole and risperidone in 75 drug-naïve first episode psychosis individuals: A 3 months randomized study. Schizophr Res 2018:202:226-33.

19 Chen C-Y, Lin T-Y, Wang C-C, et al. Improvement of serum prolactin and sexual function after switching to aripiprazole from risperidone in schizophrenia: a case series. Psychiatry Clin Neurosci 2011;65:95-7.

20 Suzuki T, Mihara K, Nakamura A, et al. Effects of the CYP2D6*10 allele on the steady-state plasma concentrations of aripiprazole and its active metabolite, dehydroaripiprazole, in Japanese patients with schizophrenia. Ther Drug Monit 2011;33:21-4.

21 Kubo M, Koue T, Maune H, et al. Pharmacokinetics of aripiprazole, a new antipsychotic, following oral dosing in healthy adult Japanese volunteers: influence of CYP2D6 polymorphism. Drug Metab Pharmacokinet 2007:22:358-66.

22 Kubo M, Mizooku Y, Hirao Y, et al. Development and validation of an LC-MS/MS method for the quantitative determination of aripiprazole and its main metabolite, OPC-14857, in human plasma. J Chromatogr B Analyt Technol Biomed Life Sci 2005;822:294-9.
23 Liu Y, Sun H-qiang, Bao Y-ping, et al. Subjective, cognitive/ psychomotor, and physiological effects of aripiprazole in Chinese light and heavy smokers. Drug Alcohol Depend 2009;101:42-52.

24 Conley RR, Kelly DL. Drug-Drug interactions associated with second-generation antipsychotics: considerations for clinicians and patients. Psychopharmacol Bull 2007;40:77-97.

25 Rajkumar AP, Poonkuzhali B, Kuruvilla A, et al. Clinical predictors of serum clozapine levels in patients with treatment-resistant schizophrenia. Int Clin Psychopharmacol 2013;28:50-6.

26 Gahr M, Schmid MM, Schönfeldt-Lecuona C. Pregabalinassociated elevation of clozapine serum levels. Pharmacopsychiatry 2012;45:297-9

27 Hard ML, Wehr AY, Du Y, et al. Pharmacokinetic evaluation of a 1-Day treatment initiation option for starting long-acting aripiprazole Lauroxil for schizophrenia. J Clin Psychopharmacol 2018;38:435-41.

28 Citrome L, Josiassen R, Bark N, et al. Pharmacokinetics of aripiprazole and concomitant lithium and valproate. J Clin Pharmacol 2005;45:89-93.

29 Citrome L. A review of aripiprazole in the treatment of patients with schizophrenia or bipolar I disorder. Neuropsychiatr Dis Treat 2006;2:427-43

30 Waade RB, Christensen H, Rudberg I, et al. Influence of comedication on serum concentrations of aripiprazole and dehydroaripiprazole. Ther Drug Monit 2009;31:233-8.

31 Nakamura A, Mihara K, Nemoto K, et al. Lack of correlation between the steady-state plasma concentrations of aripiprazole and haloperidol in Japanese patients with schizophrenia. Ther Drug Monit 2014;36:815-8.

32 Kirschbaum KM, Müller MJ, Zernig G, et al. Therapeutic monitoring of aripiprazole by HPLC with column-switching and spectrophotometric detection. Clin Chem 2005;51:1718-21.

33 Mallikaarjun S, Kane JM, Bricmont P, et al. Pharmacokinetics, tolerability and safety of aripiprazole once-monthly in adult schizophrenia: an open-label, parallel-arm, multiple-dose study. Schizophr Res 2013;150:281-8.

34 Bachmann CJ, Rieger-Gies A, Heinzel-Gutenbrunner M, et al. Large variability of aripiprazole and dehydroaripiprazole serum concentrations in adolescent patients with schizophrenia. Ther Drug Monit 2008;30:462-6.

35 Zuo X-C, Liu S-K, Yi Z-Y, et al. Steady-State pharmacokinetic properties of aripiprazole $10 \mathrm{Mg} P \mathrm{~g}$ g12h in Han Chinese adults with schizophrenia: a prospective, open-label, pilot study. Curr Ther Res Clin Exp 2006;67:258-69.

36 Molden E, Lunde $\mathrm{H}$, Lunder $\mathrm{N}$, et al. Pharmacokinetic variability of aripiprazole and the active metabolite dehydroaripiprazole in psychiatric patients. Ther Drug Monit 2006;28:744-9.

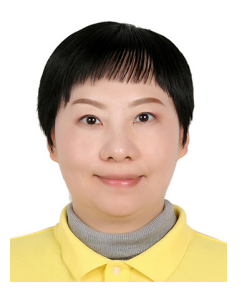

Dr. Ping Jiang obtained a PhD degree from the Department of Biochemistry and Molecular Biology, the Second Military University, China, in 2005. She is currently a research associate at the Department of Biochemistry and Pharmacology, Shanghai Mental Health Center where she has worked in since 2010. Her main research interests include therapeutic drug monitoring of antipsychotics and medical communication. 